\title{
Thierry Guèrin, Encore le corps dans «Mal vu Mal dit» de Samuel Beckett
}

\section{Stefano Costa}

\section{Q OpenEdition}

1 Journals

\section{Edizione digitale}

URL: https://journals.openedition.org/studifrancesi/39812

DOI: 10.4000/studifrancesi.39812

ISSN: 2421-5856

\section{Editore}

Rosenberg \& Sellier

\section{Edizione cartacea}

Data di pubblicazione: 1 décembre 2004

Paginazione: 411

ISSN: 0039-2944

\section{Notizia bibliografica digitale}

Stefano Costa, «Thierry Guèrin, Encore le corps dans «Mal vu Mal dit» de Samuel Beckett», Studi Francesi [Online], 143 (XLVIII | II) | 2004, online dal 30 novembre 2015, consultato il 19 mai 2021. URL: http:// journals.openedition.org/studifrancesi/39812 ; DOI: https://doi.org/10.4000/studifrancesi.39812

Questo documento è stato generato automaticamente il 19 mai 2021.

\section{(c) $(1) \&$}

Studi Francesi è distribuita con Licenza Creative Commons Attribuzione - Non commerciale - Non opere derivate 4.0 Internazionale. 


\title{
Thierry Guèrin, Encore le corps dans «Mal vu Mal dit» de Samuel Beckett
}

\author{
Stefano Costa
}

\section{NOTIZIA}

THIERRY GUÈRIN, Encore le corps dans «Mal vu Mal dit» de Samuel Beckett - Fictions du savoir à la Renaissance «Littératures» n. 47, 2002, pp. 117 - 124.

1 La vita, la morte e la resurrezione, in una metafora dell'esistenza sapientemente orchestrata, emergono, sostiene l'A., in Mal vu mal dit di Samuel Beckett da una moltitudine di voci che, pur mescolate, non giungono mai ad una fusione poetica mantenendo distinto il racconto autobiografico dall'espressione di un narratore commentatore.

2 Un corpo fisico appare integralmente nell'opera, simbolicamente incarnato nella figura di una vecchia in nero che parla solo attraverso sguardi e movimenti. L'ineluttabilità della fine costantemente incombente trasforma i silenzi tipici dell'opera beckettiana, superandoli, attraverso la parola che rinasce incarnata nella lettera rimandando la morte all'infinito grazie ad un 'testo di passaggio' che metaforicamente sospende questo vuoto per l'eternità. La paura della fine è dunque esorcizzata dal testo e dalla sua continua rinascita per mezzo di un contrasto minuziosamente ricercato e creato da un flusso continuo di espressioni sospese tra lo scatologico ed il religioso, contrapponendo l'ombra alla luce, il nero al bianco il tutto permeato da un umorismo che mette in scena riferimenti alla morte ed alla resurrezione di Cristo attraverso un simbolismo che l'A. definisce Bazar Théologique. Il registro comico della lingua e quello cupo della tonalità funebre creano un umorismo nero che, paradossalmente, si staglia sullo scenario bianco della neve, della pietra, del gesso e del calcare presenti costantemente nella storia. Il corpo fisico ed il corpo del testo giungono ad identificarsi, entrambi sacrificati in uno spazio limitato dall'economia dei mezzi in un complicato 
gioco in cui l'esperienza umana della vecchiaia si confonde con i residui dell'esperienza letteraria. 